\title{
Effect of Strathclyde Police initiative "Operation Blade" on accident and emergency attendances due to assault
}

\author{
A Bleetman, C H Perry, R Crawford, I J Swann
}

\begin{abstract}
Objective-To review assault victim attendance at the accident and emergency department of Glasgow Royal Infirmary before and after a police initiative to curb knife carrying and tackle violent assaults ("Operation Blade").

Methods-Assault victim attendance was reviewed for the month before the implementation of Operation Blade and for one month a year later. The number of victims requiring treatment in the resuscitation room for stab wounds before, during, and after Operation Blade was also reviewed as a crude indicator of the frequency of serious assaults in the city.

Results-There were no significant differences in the nature or number of assault victims attending this hospital one year after Operation Blade compared with the month before its implementation. Operation Blade reduced the number of serious stabbings for a period of 10 months, but subsequently numbers surpassed those prevailing before its implementation.

Conclusions-Any attempt to combat this complex and multifactorial problem must be addressed through a combined public health and education initiative in conjunction with regular press and police campaigns to achieve a sustained effect. $(\Im$ Accid Emerg Med 1997;14:153-156)
\end{abstract}

Keywords: knife wounds; violent crime; casualty attendance; police initiative

In the 15 years preceding 1993 there was a steady and relentless increase in violent crime in the Strathclyde Region. ${ }^{1}$ This was reflected in both the level of crime reported to Strathclyde Police ${ }^{1}$ and the number of victims of assault attending the accident and emergency (A\&E) department of Glasgow Royal Infirmary. More worrying was the concomitant increase in the number of victims of knife attacks. There was a steady rise in the number of patients with stab wounds treated in the department's resuscitation room. During the first half of 1992 these figures increased dramatically (Scottish Trauma Audit Group. Internal communication, 1994). In response to this worsening situation, Strathclyde Police devised and implemented "Operation Blade" which was intended to address the increasing tendency, particularly among young people, to carry and use knives. This study investigates how the operation affected the actual number and nature of assault injuries presenting to the A\&E department of Glasgow Royal Infirmary.

\section{“OPERATION BLADE"}

The Operation Blade initiative began in February 1993 with five overlapping phases, together with a high profile media campaign. These consisted of a knife amnesty, an intensified stop and search campaign, safety measures in places of public entertainment such as closed circuit television, metal detectors, improved lighting and training of stewards, and talks to knife retailers and secondary school pupils.

In support of this initiative the Glasgow District Licensing Board altered the termination of permitted hours in night clubs from 0300 hours to 0200 hours, and admission or readmission of patrons was prohibited after midnight ("curfew").

It is recognised that $A \& E$ data provide a useful insight into the efficiency and effectiveness of inner city policing, ${ }^{2}$ and since more than half of all assault victims attending $A \& E$ departments in the city of Glasgow are treated in Glasgow Royal Infirmary (Scottish Trauma Audit Group. Internal communication, 1994), which receives the highest proportion of assault victims attending hospitals in the Strathclyde Region, the attendances due to assault at this hospital should be a sensitive indicator of the success of such an operation.

\section{Methods}

A list of assault victims attending the $A \& E$ department was compiled for the months January 1993 and January 1994 (that is, the month before the implementation of Operation Blade and for the same month a year later). These data were collected retrospectively by a manual search of all patient records and resuscitation room log books. Epidemiological and clinical data were extracted and entered into a computerised database. Diagnoses were entered by ICD 9 coding.

Patients attending this department were triaged on arrival by a senior nurse into immediate, urgent, and non-urgent treatment categories based on the history, mechanism of injury, the appearance of the patient on arrival, and any vital signs recorded in the prehospital phase. Patients with penetrating injuries to the chest and abdomen were considered to have a major mechanism of injury and were directed 


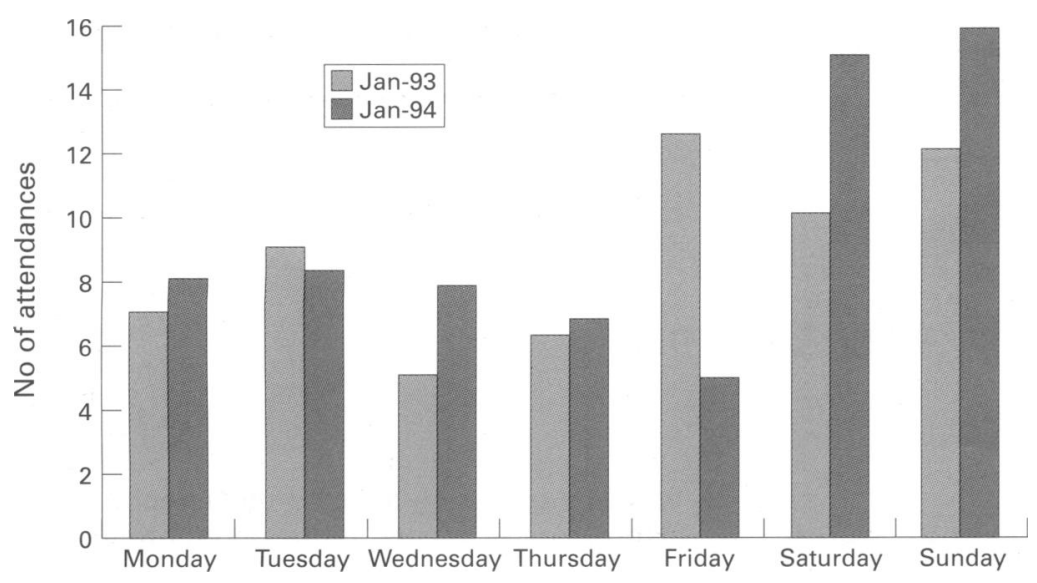

Figure 1 Average daily assault attendances.

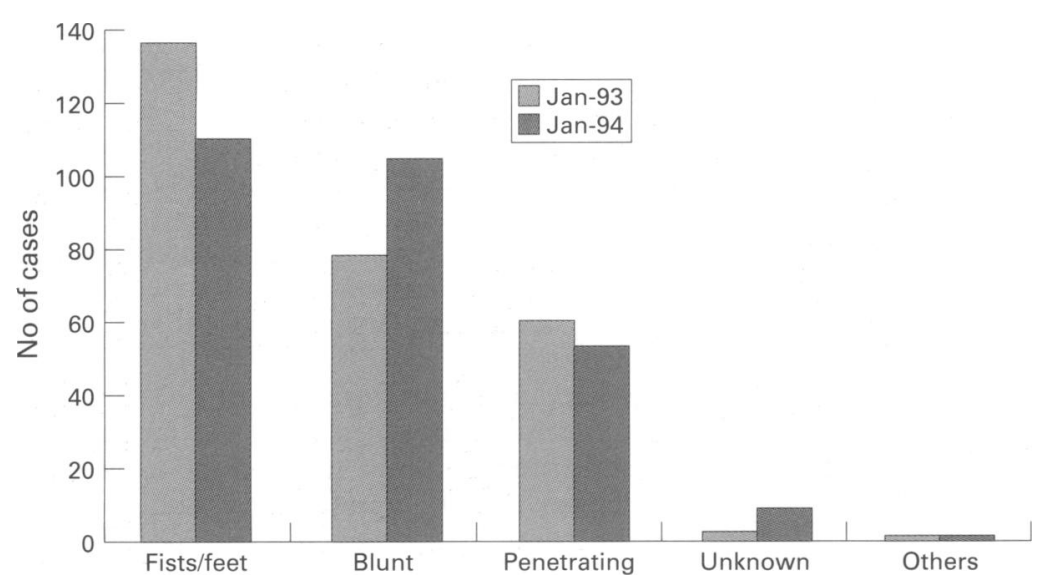

Figure 2 Mechanism of assault.

to the department's resuscitation room. A list of stab victims from January 1992 to August 1994 who required treatment in the resuscitation room was compiled as an index of the frequency of serious knife assaults. Data were analysed using the $\chi^{2}$ test and significance determined at $\mathbf{P}<0.05$.

\section{Results}

In January 1993, 282 victims of assault attended the A\&E department, and in January 1994,290 . This represented $4.9 \%$ and $4.8 \%$ of all attendances respectively; $441(77.1 \%)$ were male and 131 (22.9\%) were female. The average age was 27.8 years. There was no significant difference in the age or sex distribution for the two periods studied $\left(P>0.05, \chi^{2}\right)$.

Average daily attendances for assault are illustrated in fig 1 . Most assaults occurred at the weekend. In 1993 New Year's day fell on a Friday and thus coincided with the typical weekend surge in assaults, causing the apparent difference in Friday attendances between the two months studied.

Assault victims tended to present out of hours (between 16:01 and 08:00, table 1). There was no significant difference in the number of attendances between 16:01 to 24:00 hours and 00:01 to 08:00 hours in the two months studied ( $\chi^{2}$ test).
Table 1 Time of presentation to hospital

\begin{tabular}{lrr}
\hline Time of presentation & fanuary 1993 & fanuary 1994 \\
\hline 08:01-16:00 & $63(22.5 \%)$ & $61(21.1 \%)$ \\
16:01-24:00 & $108(38.6 \%)$ & $117(40.5 \%)$ \\
00:01-08:00 & $109(38.9 \%)$ & $111(38.4 \%)$ \\
Total & $280(100 \%)$ & $289(100 \%)$ \\
\hline
\end{tabular}

Data are not available for two patients in January 1993 and one patient in 1994.

Table 2 Mode of arrival to hospital

\begin{tabular}{lrr}
\hline Mode of arrival & Fanuary 1993 & fanuary 1994 \\
\hline Self referred & $183(64.9 \%)$ & $177(61 \%)$ \\
Ambulance & $72(25.5 \%)$ & $90(31.2 \%)$ \\
Police & $10(3.5 \%)$ & $20(6.9 \%)$ \\
Other & $10(3.5 \%)$ & $1(0.3 \%)$ \\
GP referred & $7(2.6 \%)$ & $2(0.6 \%)$ \\
Total & $282(100 \%)$ & $290(100 \%)$ \\
\hline
\end{tabular}

Table 3 Locus of assault

\begin{tabular}{lrr}
\hline Locus of assault & fanuary 1993 & fanuary 1994 \\
\hline Street & $52(18.4 \%)$ & $44(15.2 \%)$ \\
Home & $47(16.7 \%)$ & $39(13.5 \%)$ \\
Pub/club & $28(9.9 \%)$ & $30(10.3 \%)$ \\
Police station & $5(1.8 \%)$ & $1(0.3 \%)$ \\
Unrecorded & $150(53.2 \%)$ & $176(60.7 \%)$ \\
Total & $282(100 \%)$ & $290(100 \%)$ \\
\hline
\end{tabular}

MODE OF ARRIVAL

About $60 \%$ of the patients referred themselves to hospital (table 2) and less than a third of patients came by ambulance. Twice as many patients were brought to the department by the police in January 1994 as in January 1993, but this difference was not statistically significant $\left(P>0.05, \chi^{2}\right)$.

LOCUS OF ASSAULT

The locus was not recorded in over half the cases, making accurate interpretation of trends difficult (table 3).

There was no significant difference in the numbers of patients presenting with penetrating injuries or the total number of assaults during the two periods studied. In January 1993, 60 patients $(21.3 \%)$ from a total of 282 presented with a penetrating injury, compared with $53(18.3 \%)$ out of 290 in January 1994 (P $\left.>0.05, \chi^{2}\right)$. Figure 2 shows the mechanism of assault for the two months.

RESUSCITATION ROOM STABBINGS

There were 40 knife assaults in January 1993, 10 of which were triaged by senior nursing staff for treatment in the resuscitation room. In January 1994 these figures were 36 and 14 respectively.

There was a decrease in the number of serious stabbings with the implementation of Operation Blade, but this was not sustained (fig 3). The mean number of monthly stab victims triaged for treatment to the department's resuscitation room for the year preceding Operation Blade (February 1992 to January 1993) was 11.8 and that for the year after its implementation was 8.25. This apparent reduction was not statistically significant $\left(\chi^{2}\right)$.

Following the implementation of Operation Blade in February 1993 there was an average 


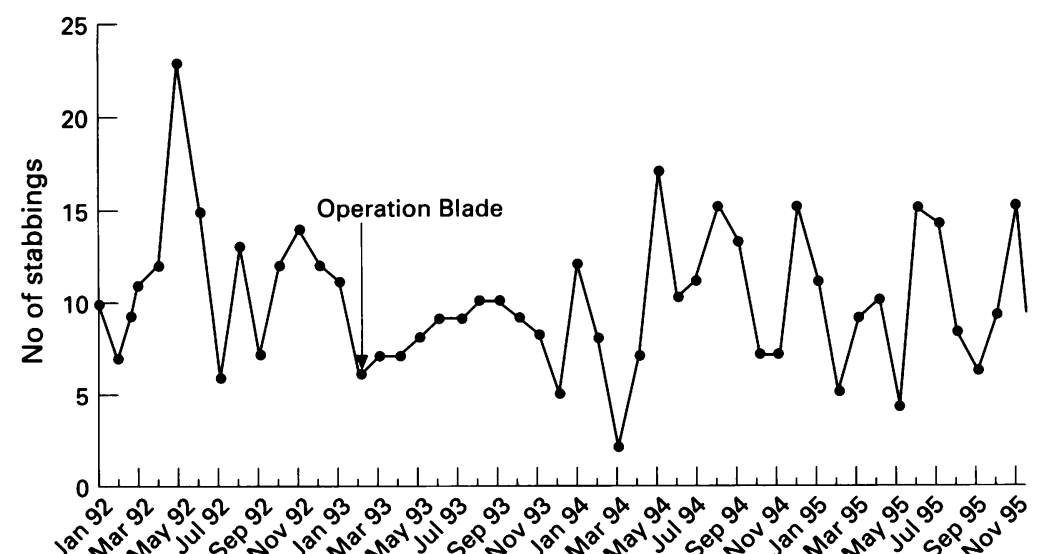

Figure 3 Stabbings admitted to the resuscitation room.

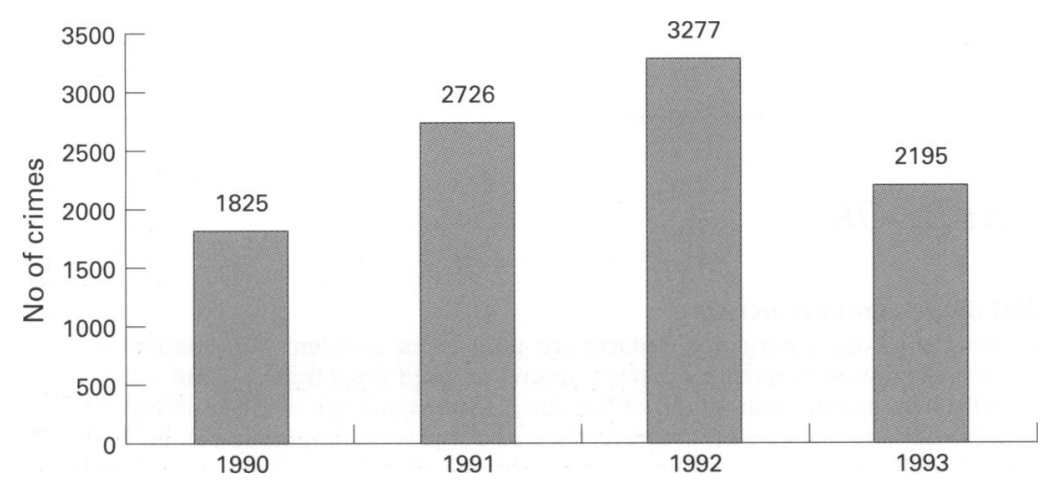

Figure 4 Crimes of violence involving knives.

monthly increase of 2.2 resuscitation room stabbings for the same calendar months in 1994. In 1995 there were an average 1.1 more resuscitation room stabbings per month than in 1993.

There was a significant increase in stabbings in May 1992 alone, which increased the overall average for that year. If this month is excluded then the apparent difference is even less impressive. After the initial decline in monthly serious stabbings, within 10 months levels had surpassed those prevailing before the police initiative. It can be seen, however, that the pattern for 1993 was different from the other years in that the wide month to month variation disappeared and the peaks of injury appeared to have been reduced.

\section{Discussion}

The stated objective of Operation Blade was "to impact on the growing tendency for persons to carry and use knives and similar weapons and to reassure the public that Strathclyde Police is aware of and tackling the problem." It was intended "not simply as a reflex reaction to a rise in particular crimes, but rather as a fundamental means of addressing the apparently acceptable 'culture' particularly among young men who were increasingly carrying and using knives". ${ }^{1}$ Strathclyde Police figures indicated a profound and maintained decrease in the incidence of reported violent crime in the wake of Operation Blade. The Police stated that "figures relating to crimes of violence during 1993 revealed an overall reduction of $19 \%$ in comparison with 1992" and that "the most significant figures are those concerning the level of crimes of violence committed involving the use of a knife. Figures for 1993 indicate a reduction of $33 \%$ in comparison with 1992" (fig 4).

It is well recognised in published reports that less than half of violent crime is in fact reported to the police, ${ }^{2}$ whose figures can only reflect reported violent crime. There have been many series published worldwide describing the epidemiology of urban assault patterns. ${ }^{3-5}$ Our data show broad epidemiological similarities with other studies of assault patterns: assault victims tend to be males in their late $20 \mathrm{~s}$ presenting "after hours" at the weekend. ${ }^{3}$

We acknowledge that triage criterion for patient admission to the resuscitation room is a crude indicator of the frequency of serious assaults in the city; however, there were no changes in ambulance service practice or nurse triaging policy before, during, or after Operation Blade. Future studies would need to establish more objective and reproducible criteria for resuscitation room triage. Our figures do show a profound initial decrease in stabbings with the implementation of Operation Blade, in agreement with the Police data. This coincided with the saturation of the city centre by police officers during the introduction and early enforcement of Operation Blade. However, there then followed a steady increase, so that within a year the effect of the operation appeared to have passed. It is interesting to note the reduced month to month variability of serious stabbings admitted in 1993 after the implementation of Operation Blade. We consider this to be a reflection of the increased police presence in the city centre, particularly at pubs and clubs.

Increased police presence and the introduction of the clubs' curfew had no significant impact on average daily attendances or on the time of attendance. We conclude, therefore, that in spite of police optimism, the impact of Operation Blade was not sustained.

It is interesting to note that the number of patients brought to hospital by police rose from $3.5 \%$ to $6.9 \%$ during the period of study. While not statistically significant, this may reflect the higher police presence on the streets and at pubs and clubs in the city after the introduction of Operation Blade. Unfortunately the locus of the assault was not documented in more than half of the cases, which made it difficult to determine whether these measures achieved one of their aims in reducing violence in pubs and clubs in the region.

In order to maintain decreased levels of violence, this type of operation would have to be repeated at regular intervals, as with the annual drink-drive campaigns, so that social and cultural attitudes may be changed in the longer term. The problem is multifactorial and the challenge is great but it must be addressed through a combined public health and education initiative in conjunction with press and police campaigns. In the meantime the most 
effective strategy to reduce these crimes would appear to be a strong and visible police presence during the periods of greatest risk.

The computerised Hospital Trauma Registry Project was funded by a grant from the Area Medical Audit Committee of Greater Glasgow Health Board. The Scottish Trauma Audit Group (STAG) was funded by a grant from the Scottish Office Clinical Resource and Audit Group. We wish to thank Ms Sarah Shrouder of STAG for her assistance in data collation for this study.
1 Strathclyde Police report on 'Operation Blade', 1994.

2 Shepherd JP, Shapland M, Scully C. Recording by the police of violent offences; an accident and emergency department perspective. Med Sci Law 1989;29:251-7.

3 Shepherd JP, Scully C, Shapland M, Irish M, Leslie IJ Assault: characteristics of victims attending an inner-city hospital. Injury 1988;19:185-90.

4 Shepherd JP, Farrington DP. Assault as a public health problem: discussion paper. J R Soc Med 1993;86:89-92.

5 Shepherd JP, Robinson L, Levers BGH. Roots of urban violence. Injury 1990;21:139-41.

\section{EMERGENCY CASEBOOK}

\section{Traumatic intrapericardial diaphragmatic hernia}

A 69 year old woman was brought to our emergency department after a car accident. The patient was haemodynamically stable and was diagnosed as having a pelvic fracture, a closed tibial fracture, and multiple left sided rib fractures on an otherwise normal radiograph of the chest. Osteosynthesis of the tibia was performed. On the first postoperative day a repeat chest radiograph showed a supradiaphragmatic colonic haustration pattern suggesting the possibility of a diaphragmatic rupture with herniation of colon into the chest. Computed tomography of the chest confirmed the defect in the central part of the diaphragm with intrapericardial herniation of the colon. At laparotomy through a left subcostal incision a $10 \mathrm{~cm}$ tear was found in the pericardial diaphragm. Part of the stomach and the transverse colon had herniated into the pericardium. The herniation was easily reduced and the lacerated diaphragm was repaired with interrupted non-absorbable sutures. Postoperative recovery was uneventful.

$C T$ scan of the chest: intrapericardial herniation of transverse colon due to traumatic rupture of the central part of the diaphragm

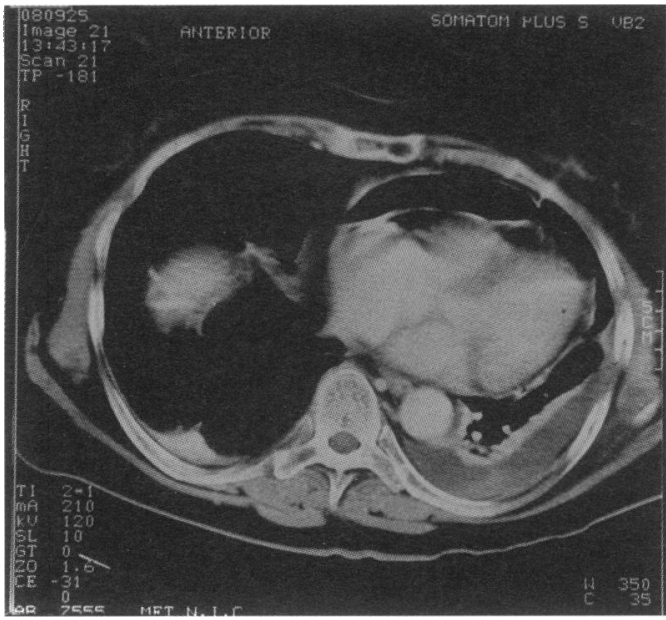

Traumatic diaphragmatic rupture (TDR) results from blunt or penetrating thoracoabdominal trauma and is diagnosed in $0.8-2 \%$ of multiple trauma admissions; an estimated $5 \%$ of patients need a laparotomy after blunt trauma. Isolated rupture of the central part of the diaphragm resulting in an intrapericardial diaphragmatic hernia is almost never mentioned in large reviews of TDR. The literature consists mainly of case reports. Diagnosis was made by chest radiograph 24 hours after admission and confirmed by CT scan. Our case supports the need for serial radiographs of the chest in multiple trauma patients. A high degree of suspicion is needed to allow detection of signs pointing to the possibility of TDR. In more than $50 \%$ of cases diagnosis is made during surgery, either laparotomy or thoracotomy. Traumatic diaphragmatic rupture is practically always combined with associated injuries. The prognosis is determined by the seriousness of the associated injuries. More than half of patients with TDR need postoperative ventilation. There is an overal mortality of $21 \%$ to $41 \%$. F MUYSOMS, H VERHELST, H SCHROË, Department of Vascular and Thoracic Surgery, R DE JONGH, Department of Anaesthesia and Intensive Care, St fansziekenhuis, Schiepse Bos 2, 3600 Genk, Belgium 